\title{
Article
}

\section{The role of 'pracademics' in education and development of adventure sport professionals}

\author{
Collins, L., and Collins, D.
}

Available at http://clok.uclan.ac.uk/22667/

Collins, L., ORCID: 0000-0002-7478-1140 and Collins, D. ORCID: 0000-00027601-0454 (2019) The role of 'pracademics' in education and development of adventure sport professionals. Journal of Adventure Education and Outdoor Learning, 19 (1). pp. 1-11. ISSN 1472-9679

It is advisable to refer to the publisher's version if you intend to cite from the work. http://dx.doi.org/10.1080/14729679.2018.1483253

For more information about UCLan's research in this area go to http://www.uclan.ac.uk/researchgroups/ and search for <name of research Group>.

For information about Research generally at UCLan please go to http://www.uclan.ac.uk/research/

All outputs in CLoK are protected by Intellectual Property Rights law, including Copyright law. Copyright, IPR and Moral Rights for the works on this site are retained by the individual authors and/or other copyright owners. Terms and conditions for use of this material are defined in the policies page.

\section{CLoK}

Central Lancashire online Knowledge www.clok.uclan.ac.uk

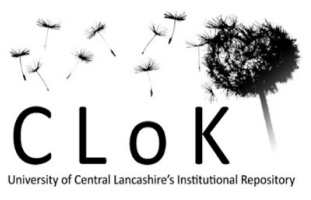


The role of 'pracademics' in education and development of adventure sport professionals

\author{
Loel Collins* and Dave Collins
}

Institute of Coaching and Performance, University of Central Lancashire, Preston, PR1 2HE, UK

*Correspondence concerning this article should be addressed to Loel Collins, Institute for Coaching and Performance, University of Central Lancashire, Preston, UK, PR1 2HE. Email: LCollins2@uclan.ac.uk. 


\begin{abstract}
Understanding and exploiting the synergy between theory and practice lies at the heart of effective education for outdoor professionals. Accordingly, and in an attempt to stimulate debate, this paper conceptualises the interaction between theory and practice in the context of the education of outdoor professionals. We identify issues specific to the often separated worlds of practice and academia. While acknowledging those distinct skills and competencies, however, we also explore a mid-role; that of the 'pracademic' or scientistpractitioner or practioner scholar, considering behaviours that may encourage greater collaborative work to inform the process and implementation of the education of outoor professionals.
\end{abstract}

Keywords: Coach, Leader, Guide, Instructor education, philosophy, 
Understanding and exploiting the synergy between theory and practice lies at the heart of effective education for outdoor professionals. Accordingly, perhaps, the last two decades have seen a growing consensus that research, if judiciously applied, improves practice (Abraham \& Collins,2011). Unfortunately, research and experience has also highlighted the 'deep ravine'(Tunison, 2016) between theory derived from research and real world practice. Evidence based practice, as originally conceived combined the findings of research and the experiences of the user (consider, Sachett, 1996) offered a pragmatic route forwards. However, evidence based practice, appears to have slowly given way to a more polarised research driven practice and an almost opposing, belief based practice (Rushnell, 2003). Drawing these poles back together generates a challenge to reintegrate practice and theory. The challenge has been the subject of lengthy debate, is a focus of some research by academics and complaint by practitioners, and is by no means new. Unsurprisingly, research into this synergy has been conducted by academics, implicitly suggesting research as the sole domain of the academic. In an attempt to offer a balanced 'mid point' position, increase clarity and stimulate debate, this paper conceptualises the interaction between theory and practice from the bridging perspective of the coach and leadership educator role. The aim being to acknowledge the importance of bringing together theory and practice in the process of educating coaches and leaders in adventure sports and to introduce the concept of 'pracademic' in this area.

Firstly, we present a brief overview of perspectives and the approaches to theory to practice synergy. Secondly, we identify issues specific to each group; the coaches, coach educators and academic stakeholders, considering the origins of a redefined mid ground role, that of a 'pracademic' (McDonald \& Mooney, 2011), as a means to increased integration. Finally, we consider behaviours that may encourage greater collaboration between stakeholders that may be facilitated by the pracademic.

\section{An Overview}


Links between theory and practice are crucial for effective coach and leader education; these links, however, run both-ways (Christina, 1987). Undoubtedly, theory serves as a foundation to practice but practice and application should also serve as the catalyst to derive theory. Thus, good theory informs the education of coaches and leaders while practice exposes practical challenges requiring a structured research intervention and identify inappropriately developed theory. Coach and leader education shares this long-standing, challenge with other domains such as medicine, journalism, business and engineering. In all these practical domains, a tension is apparent (and often acknowledged) between those who do and those who write about it. Positively, the goal and challenge for many applied researchers in these fields is to bridge this gap (cf. Gray, 2014; Robson, 2011; Tunison 2016).

Within the education of outdoor professionals, the linkage of academia and practice is attempted via formal programmes of training in which research and practice are juxtaposed. Presumably, the synergetic relationship exposed and addressed results in the crossing of Tunison's (2016) ravine. These programmes vary in length, content and philosophy. Piggott (2015) contends that coach education is frequently characterised by a technical rationality, follows a 'one size fits all pedagogy' (p. 5) and draws on behaviourist paradigms. Such approaches may have led to the change in evidence based practice highlighted earlier by reducing coach and leadership education to a transactional relationship rather than transformational. Such a position appears in distict contrast with the conceptualisations of the adventure sports professional (see Collins \& Collins, 2012; 2016 for example) in which the professional requires a distinct set of technical and cognitive skills in order to practice safely and effectively. Indeed, we suggest that this approach is also characterised by a naïve epistemological position (Schommer, 1994) on the basis that a solution is unlikely to be the single approach advocated in such programmes and the learning process in managed by the coach educator to meet the requirements of the awarding body in contrast to the developmental needs of the trainee. Such an approach lies in contrast with Schommers (1994) notions of a sophisticated epistemological position in which a more constructivist, adaptable and flexible approach places the learner as central to the process. Notably, Abraham and 
Collins (1998), Jones (2006) and Schempp (1998) have all highlighted the limitations of naïve, dogma driven approaches, and considered different perspectives and solutions to the challenge.

Against this backdrop, Nelson, Cushion and Potrac (2013), Piggott (2012), Cassidy, Potrac and McKenzie (2006) and McCullick, Belcher and Schempp (2005) all comment that coaches seek interactive approaches to coach education. Such methods suggest an approach that, at least outwardly, appears to align the desires of the trainee coaches and leaders for a constructivist approach together with, perhaps, the more sophisticated view of education held by more experienced and reflective practitioners (Collins \& Collins, 2014). This constructivist position is advocated by Werthner and Trudel (2006), Werthner, Culver and Trudel (2012) and Trudel, Culver and Werthner (2013); namely, a move towards a sophisticated epistemological position for both coaches and coach educators (Schommer, 1994). Notably, this reflects observations of good coaching and effective coach education practice (Collins et al 2016) and reflects approaches in other educative domains (cf. Jones, 2006).

Focusing on coach behaviour is not without its critics, however. For example, a challenge to these behaviourist approaches is identified by Saury and Durand (1998) who suggest that many coaches are left to contextualise and make sense of pan-sport theories via their own experiences (both their specialist sport and coaching.) As a result, a perceived balance between the formal aspect of training and the 'hands on' experience is frequently required. However, this is achieved in an ad-hoc manner, with prerequisite experiential requirements applied between training and assessment being the limit of advice offered on maximising that component. While ad-hoc contextualisation may have some value from a constructivist perspective, or in the development of key cognitive attributes such as metacognition, an additional set of 'learnacy' skills (Claxton, 2002) would also seem to be required by the coach, to contextualise and transfer that generic knowledge into their own practice. Giannini, Krane and Hodge (1990) highlight a weakness in that constructed/contextualised knowledge as being dependent upon the individual's interpretation 
and perception of their own experience of being coached and their own coaching. In turn, this would be dependent on the breadth and depth of that experience, the person's openness to challenge and change and, most crucially, the effectiveness of the coach's own reflective processes and metacognitive capacity. In this regard, Collins et al (2016) argue that the coach and leader requires metacognitive skills to optimise reflection on those experiences and to effectively perceive both their own performance and that of others (cf. Kruger \& Dunning, 1999).

Of course, these additional skills must also come from somewhere, but who should provide them is not yet clear. We would have to question whether these 'learnacy' skills and the essential metacognitive skills described above are possessed or developed in trainee coaches by the behaviourist approaches highlighted earlier. Certainly, the capacity to learn from experience is rarely evaluated or taught in the technically focused, one size fits all approaches to coach and leader education in this context (Piggott, 2015; Abraham and Collins, 1998). Of course, this message is not new; however, its longevity is alarming.

Collins, Collins and Willmott (2016) guard against simplifying coach education to any single paradigm, preferring a "right tool for the right job" approach driven by a refined Professional Judgment and Decision Making (PJDM) process. Extending this contention, we suggest that advocates of a single paradigm miss the point; namely, the ability to be adaptable and flexible in the field in order to find or fit the right tools to the job. We would also suggest that this perspective lies in contrast to much of the recent literature, including perhaps some of our own, in which, although a single paradigm may not be directly advocated but is implicitly encouraged! As examples, please consider competency-based programmes (Demers, Woodburn \& Savard, 2006), constraints led coaching, (Davids, Button \& Bennett, 2008), issue-based learning (Trudel \& Gilbert, 2006), transformative learning (Taylor \& Collins, 2016), problem-based learning (Jones \& Turner, 2006; Ojala \& Thorpe, 2015), communities of practices (Culver \& Trudel, 2006), the work placed curriculum (Billett, 2002), models of working life (Illeris, 2004), and the comprehensive work-based model (Raelin, 2008). These authors universally advocate the need for a diverse approach to 
coaching, coach education and coach assessment. However, the implication, writing and review process frequently results in a more didactic presentation. Irrespective of whether the authors' intention is to drive forward practice, the message is often lost in the medium.

Plural paradigm and mixed research enable results to expanded beyond the those that may have been missed utilising a single approach. Additionally, the strengths of a mixed approach offset the weaknesses in individual quantitative and qualitative rapproaches. Both quantitative researches contextual weaknesses and qualitative researches potential for researcher bias or difficulty in generalizing findings to a large group can be managed in mixed approaches. Clearly, mixed provides a more complete and comprehensive understanding of the research problem than single approaches alone. The particular advantages in adventure sports is the capacity to develop context specific instruments, which in turn explain causal processes and findings in context. However, research design can be complex, time consuming, difficult to plan and make high demands on Rescources and researcher alike. Importantly it may be challenging to resolve discrepancies and anomalies that arise in the interpretation of findings. Not with standing, It seems likely that such approaches provide the highest probability of successfully meeting the varied objectives implicit within a pragmatic approach.

From the medium perspective there are some efforts apparent to close the gap. Open access journals and repositories in the UK and approaches such as the Journal of Outdoor Research and Experiential Learning in the US, in which a third of the journal content is dedicated to practitioner written, not just focused, papers, offer models that recognize the need for integration. Others, such as Alexandra Elbakyan with Sci-hub offer more controversial routes to accessing academic work. The longer standing approaches to compile papers and publish compendiums of work from academics may reduce expense (an additional deterrent to coaches) but does not fully address the inaccessibility of the writing style. These tendencies, perhaps, lead to a counter growth in more easily accessible and popularized (at least with coaches) books such as Bounce (Syed, 2010) or the Chimp Paradox (Peters, 2012) 
which are more accessibly written but which lack the rigor expected, even essential, in peer reviewed publication. In its self-reflecting the conundrum, the peers to the academics are academics and for the coaches and leaders other coaches and leaders. Despite these efforts, the perceived complexity of academic writing remains a block to effective communication between theorists and practitioners.

This block is further compounded by the coach education workforce, driven by their own epistemologies or those advocated by their training authority, the time and financial constraints of education/ training programs that reduce the process of education to the simplistic identified by Piggott (2015) or the 'indoctrination' identified by Nelson, Cushion and Potrac (2006). Despite the research time and effort that has been spent in understanding coaching, these findings are often not reflected in coach and leader training or education because of the predominant 'behaviorist', research driven tendencies of the coach educative process. Despite the growing wealth and breadth of the research that highlights the need for change (Nelson et al., 2013) it is rather slow in coming and, consequently, the debate continues on as positions polarize further.

\section{Stakeholders in Adventure Sports Coach and Leaders}

\section{Education}

Reflecting our arguments above, the challenges for education are varied and involve the perception which coaches and leaders have of theory, their understanding of how it is derived and their access to that research. In an effort to understand this complexity, we consider the current stakeholders who play an active role in the education of coaches and leaders, namely, the academic, coach and coach educator and introduction the notion of the pracademic.

\section{Academic}

Posner (2009) suggests that academics are likely to have clearer and more stable career paths within institutions. These institutions value, support and encourage an academic's research pursuits. This research combines personal insights and material gathered 
through a focused process of investigating a particular topic. In this view, the process of research, critical thinking, evaluation, and organization combines primary and secondary information sources into a supported, testable and repeatable claim. Changes to reflect real world impact of research for the British Research Excellence Frameworks adopted in 2014 clearly indicate an intention for change and reflect the concerns regarding the connections of research to the real world, a political pressure for greater integration.

\section{Coach and Leader.}

The coach's role does enable practical interdisciplinary contribution to a field in a focused and immediate way. In particular, the coach is free from the constraints of academia and academic delivery but differentially constrained by the demands of athlete/student and environment. In this respect, s/he is free to 'experiment', adapt and refine knowledge (cf. Schön's, 1983 view of practitioner as experimenter) and theories (and, therefore, practice) directly in context and in a highly pragmatic way (L. Collins \& Collins, 2015, 2016a, 2016b). But is less, or perhaps willing, able to formalise or share their findings.

\section{Educator}

Coach educators develop from the sources highlighted above. Notably, however, there is a growing body of training educators who specialise in delivering education but who do not reside comfortably in either of the groups highlighted above (cf. MacNamara \& Collins, 2015) but do originate within either of the coaching or academic areans. Whatever their genesis, the role of the educator is varied and reflects the individual's route into and motivation for being in education. Consequently, this may perpetuate the schism highlighted earlier because the educators lack the full knowledge of the integration between the academic and practice and possibly the academic or the practice. The role of coach educator remains very broad and appears to be broadening as the schism itself gets wider. This void in the relevant and accessible knowledge gives rise to the education blogger that reduces education to little more than journalism of the fashionable paradigms (cf. MacNamara \& Collins, 2015) or personalised attacks between advocates of different approaches. As the Tunisons (2016) 'ravine broadens' the behaviourist coach educator fails to fill the void, perhaps by overly 
simplifying the complexities in favour of sound bites, impact or confrontation at the expense of criticality of the coach, the approach, the research or the presentation.

\section{A Pracademic Position and Perspective}

Importantly, a logical and grounding bridging role is emerging. McNiff and Whitehead (2009) commented that both teachers and coaches are valued as practitioners but not as researchers. This 'research gap' (whether actual or perceived), can be effectively bridged by a pracademic role, however. As stated, coach educators are frequently derived from practice or theoretical backgrounds, few appear to successfully inhabit (or have inhabited) both worlds and are, therefore, clearly influenced by their respective origins and motives. Of course, at a fundamental level, effective coach education needs to reflect authenticity, relevance and trustworthiness (Chesterfield et al., 2010). Accordingly, coach education needs to be supported by relevant theory and empirical evidence, derived from observation or experience and both academic and coaches practice, thus enabling genuinely evidence-based practice. Reflecting our observations so far, a need emerges to fill the gap with interdisciplinary knowledge, not simply bridge it or narrowing the gap.

It seems logical to consider that the differing cultures contribute to the apparently polarised positions of these respective stakeholders. It is likely, however, that a more general problem with adapting theory to practice is present throughout all coach education, which fundamentally relies on effective linkage based on understanding the nature of that relationship. Indeed, there seems little doubt that the complexity of coaching and leadership exacerbates this problem, furthering the need for an integrated focus between practice and theory through a more specialised, median role. To our minds, the value of each other's contribution appears to be based on perceptions of either sides' credibility measured against the perceiver's own criteria, our point earlier regarding peer review for instance - a rather challenging position in which a common understanding of the shared goal would seem essential.

\section{How Might the Gap be Filled?}


We suggest that, for coaching and leadership education to progress and the schism filled, three aspects require consideration;

\section{Firstly; a perception of context.}

To know how to act in context, the educator needs to perceive and understand those factors that influence and constrain that context; in short, to have a contextual framework and cultural sensitivity to the activity. This understanding of the contextual frame and cultural sensitivities is essential, and is perhaps what the coaches focus on and feel that the academics miss. This is clearly apparent in the literature as the relevance to practice highlighted by Winter and Collins (2015), or in statements such as "....the voice of the teachers" mentioned by Cochran-Smith and Lytle (1990, p. 1).

\section{Secondly; an informed intellect.}

Understanding absolute fundamentals in order to be practical requires an informed intellect, declarative knowledge of the activity and of the pedagogy (cf. Abraham \& Collins, 1998). We inform our intellect of these absolutes (for example, the criteria against which a coaching decision could be judged) by contemplating the nature of every positive and negative aspect of practice (reflection in and on practice). To be practical, we need the knowledge of the 'what' (perhaps what the academics focus on) and the why (as an example, the focus of recent work in PJDM).

\section{Thirdly; a practical wisdom.}

In this context, the Aristolian notion of Phronesis, or 'practical wisdom' (Schwartz, 2011), provides the connecting capacity that enables the reflection, deliberation, judgment and reasoned action in practice which inturn contributes to the evidence based practice highlighted earlier. This is, also, a manifestation of the metacognition highlighted earlier. This application, rather than just replication of the useful knowledge, links context and knowledge: the ability to do the right thing, at the right time. This is not dissimilar to Kelchterman's $(2005,2009)$ notion of a personal interpretive framework and links this role to the constructivist paradigms highlighted earlier. This is the focus for the pracademic, one that explicitly links the context and knowledge while comprehending the demands of those links ( 
see situational demands, Abrahams \& Collins, 1998).

As well as these constructs, there is an, at least perceptually, argument on how they are gained. For example, some coaches may argue that practical coaching skills can only be gained through experience; unfortunately that position fails to recognise the act of learning from that experience as essential. As Huxley (1933) suggests, experience is not what happens to someone, it is what they do with it. Such a position contrasts with one that advocates having the knowledge as enough (a Socratic or Platonian perspective) and assumes contextualization will naturally occur. Neither appears to fully comprehend the complexity of the coaching and leadership or the context for the adventure sports professional. It seems likely that perception of context and informed intellect has a synergy to enact via 'practical wisdom' and metacognition which may facilitate the pracademic as coach educator.

\section{Next Steps: Potential Models and Systems for Practice}

Pracademics are well established in many fields (e.g., education and clinical psychology; Shapiro, 2002) and, although terminology may differ across domains, the desired outcome appears identical; to modify practices and fill the gap between academic and practitioner appear consistent.

\section{The Pracademic Term (c: 1973-2016)}

A pracademic is someone who is both an academic and an active practitioner in their subject area. The term has a history of at least 30 years, with references appearing in the early 1970s. More recently, Posner (2009) and McDonald and Mooney (2011) discussed the term and have used it in publications. Both Volpe and Chandler (2001) and Price (2001) have also described the role associated with "pracadeamia". In the citations above, a bridging concept appeared to be the main theme. The antecedents of the pracademic term appear to stem from two models advocated in Psychology.

The Boulder Model (Lane \& Corrie, 2006) developed to generate an applied psychologist trained to be a competent researcher and practitioner; one who can both generate and apply knowledge. This approach to education leads to professional, evidence-based 
practice in which practitioners adhere to scientific methods, procedures, and research in their day-to-day practice. The goal being to use scientific methodology in practical decisionmaking. The Boulder Model has clear academic antecedents: assessment and intervention based on scientific protocols, integration of scientific findings to inform decisions, positivist informed decisions, collaboration with related professionals, and evidence-based practice (both research and clinical) that contributes to a growing knowledge.

The Vail Model (Lane \& Corrie, 2006) focuses on clinical practice and emerged from the Boulder model. The model proposes that the effective practitioner is, at the least, a consumer of research; a highly trained professional who applies knowledge and techniques to solve problems. This model is practitioner-oriented. It focuses on clinical practice rather than academic knowledge per se, and is structured around the application of knowledge, extensive experience and research consumption.

Building on these two positions, Lane and Corrie (2006) and Kennedy and Llewelyn (2001) advocate a model that catered for changes in context and reflected a mid-ground use of the term that is more akin to pracademic. Citing Wheatley (1999), the broad parameters originally conceived in the Boulder model have become constraints. What were initially guidelines have become rules that have constrained the use of the term. Accordingly, Corrie and Callahan (2000) advocate a more flexible use of the term "scientist" that overlaps with the Vail model. This position recognises the essentially academic style of judgement and reasoning required by practitioners in complex contexts such as coaching. This shift has "centralised" the position of the pracademic. Indeed, Lane and Corrie (2006) describe this position as the new scientist-practitioner in terms of its position relative to practitioners and scientists although this terminology seems to imply a degree of bias. Our preference remains as pracademic because it places the practitioner clearly in the relationship.

\section{What Might This Look Like?}

\section{A Research Position}


Tunison (2016) proposes a range of reasons for this theory-practice divide, amongst them is access to primary research (reflecting our points earlier). He also comments on the ebbs and flows of 'well-intentioned' research simply leading to scepticism amongst practitioners and a reduction in the credibility of academic research. The (at least perceived) lack of synergy between what practitioners regard as important and the topics on which academics publish is arguably the most significant barrier, particularly in applied disciplines such as those represented by this journal. So, in other words, academic work is often perceived by practitioners as too focused, too esoteric, or just simple common sense which offers little to their practice. In parallel, academics can perceive practice as dated, opinion driven and closed to innovation. What is required is an understanding of how coaches and coach educators perceive the theory generated by research.

One aspect of this challenge may be the way in which research is conducted. Lueger (2002) recognised a need for a methodology that could address this void, preferably based (on our earlier contentions) on reciprocal action. As earlier approaches, both Gibbons et al.'s (1994) and Tranfield and Starkey (1998) conception of mode 1 and 2 research practices offered a methodological position in which research informs practice and practice drives research. Mode 1 research is investigator-initiated and discipline-based, while mode 2 research is problem-focused, inter/multi-disciplinary and contextual (cf. Christina, 1987; see also Winter \& Collins, 2015). In building on this distinction, MacLean, MacIntosh and Grant (2002) attempted to map mode 2 features against action research, cooperative enquiry and grounded theory. Phenomenology, interpretive phenomenology, thematic, narrative, conversation and discourse analysis, and focus groups may also all reside within the mode 2 methodological position. The value of these approaches is the depth, breadth, and richness of the data collected but lack the generalisability desired by some researchers. Importantly, mode 2 may seem appealing but may not align with some practitioners perception of research.

Notably, this contrasts with Christina (1987) who identified the challenge of this interdisciplinary research by identifying three levels of research based on the research's relevance in practice; basic research (level 1) as developing theory-based knowledge with " 
no requirement to demonstrate its value for solving practical problems'; research that should demonstrate a delayed value in practice (level 2) or finally immediate impact (level 3). As stated, coaches may focus in their 'experimentation and research', coaching (Schön's, 1983 view of practitioner as experimenter) to solve problems that inhabit levels 2 and 3 while the academic may be focusing research in level 1 . While appealing in its simplicity, the void remains between levels 1 and 3 with level 2 never fully meeting the neds of academic or practictioner.

A pragmatic position towards research in which a focus is derived from real world issues, reflects the historic and cultural norms of the activity and is multi layered offers a convenient paradigm on which to hang such approaches but still cannot provide the big solution that may be sought after by the coach. Simultaneously having the potential to bring together differing approaches while also simply offering another approach to be challenged. However, street credibility for coaches and leaders is based around application and immediate impact, as opposed to the longer duration, 'portfolio' building criteria used by academics. Consequently, coaches and leaders look for immediate pragmatic solutions to the problems they face in the real world, relying (perhaps overly?) heavily on a perceived intuition and experience to build personalised theories of practice via a process of individual experimentation and reflection.

Inter-disciplinary, between academic and practice, research is formally encouraged in the literature, although it is still under-represented and, tacitly, viewed as a lower level of research in academic circles, despite its links to the coach's practice. This contrasts directly with the needs of practitioners for an explicitly applied and almost inevitably interdisciplinary focus which reflects the dynamic nature of their work. Bond and Campbell (2008) proposed that any research clearly defines its target group demonstrates rigor, can be independently replicated, addresses important needs in the target population, and is capable of application in a wide range of contexts. In short, research should be translatable into practice, addressing questions that need to be answered and presumably posed, initially, by the practictioners. However, this "practical shift" is often perceived to weaken investigative rigor; an argument 
used to undercut the value of applied research. Conversely, the same attributes of applicability, immediacy and uniqueness that challenge academic notions of quality, would increase perceived value from a practitioner's position.

Against this backdrop, it should also be acknowledged that academics and practitioners can both often fear rather than relish (especially if they are genuinely pragmatic) interrogation of the relevance of their practice by their paradigmatically distant cousins (researcher to practitioner and vice versa). In contrast, and perhaps unsurprisingly, each enjoy the social interaction with colleagues of similar backgrounds and interests, sharing a common language, common philosophy and comprehension of their body of knowledge; a process which Hambrick (1994) describes as an “... incestuous, closed loop” (p. 13). Importantly, we suggest that this criticism can apply to academic and practitioner alike.

We would note, at this point, recent attempts, such as the Adventure sports coaching conference at Plas y Brenin, The National Mountain Centre in the UK (11-12th January 2018) that attempted to bring together practitioner, academic and coach educators in adventure sports. It is too early to see if such approaches for collaboration are effective in the mid to long term

\section{Conclusion}

While academics and practitioners clearly have significant commonalities, the value systems of the different institutions polarise the respective positions, contributing to a dangerous and dysfunctional disconnect in leadership and coaching. This void may potentially be filled by a third party, the pracademic, as advocated by Price (2001) and McDonald and Mooney (2011). If we are not careful, however, such a position could potentially "cement" (both filling and perpetuating) the divide. The adoption of mode 2 research approaches (Gibbons et al., 1994; Tranfield \& Starkey, 1998) to investigate the perceptions of coaches and coach educators towards research may necessitate a shift from the current polarised positions and offer the opportunity for further investigation that, we think, may provide the catalyst to unlock this puzzle. The potential findings could result in the identification of a more common set of 
behaviours, in research and in education which could be considered as pracademic, that bring authenticity and a relevance to coach education. We hope to have stimulated some thought and debate across the wide-ranging landscape which clearly exists. 


\section{References}

Abraham, A., \& Collins, D. (1998). Examining and extending research in coach development. Quest, 50, 59-79. doi:10.1080/00336297.1998.10484264

Abraham, A. \& Collins, D. (2011). Taking the Next Step: Ways Forward for Coaching Science. Quest, 63, 366-384.

Berry, M., Lomax, J., \& Hodgson, C. (Eds.). (2015). Adventure sports coaching. Abingdon: Routledge.

Billett, S. (2002). Workplace pedagogic practices: Co-participation and learning. British Journal of Educational Studies, 50, 457-481. doi:10.1111/1467-8527.t01-2-00214

Bond, G. R., \& Campbell, K. (2008). Evidence-based practices for individuals with severe mental illness. Journal of Rehabilitation, 74(2), 33-44.

Cassidy, T., Potrac, P., \& McKenzie, A. (2006). Evaluating and reflecting upon a coach education initiative: The $\mathrm{CoDe}^{1}$ of rugby. The Sport Psychologist, 20, 145-161.

Chesterfield, G., Potrac, P., \& Jones, R. (2010). 'Studentship' and 'impression management' in an advanced soccer coach education award. Sport, Education and Society, 15, 299314. doi:10.1080/13573322.2010.493311

Christina, R. W. (1987). Motor learning: Future lines of research. In M. J. Safrit \& H. M. Eckert (Eds.), The cutting edge in physical education and exercise science research (pp. 26-41). Champaign, IL: Human Kinetics.

Claxton, G. (2002). Building learning power: Helping young people become better learners Bristol: TLO Limited.

Cochran-Smith, M., \& Lytle, S. L. (1990). Research on teaching and teacher research: The issues that divide. Educational Researcher, 19, 2-11. doi:10.3102/0013189x019002002

Collins, D., Burke, V., Martindale, A., \& Cruickshank, A. (2015). The illusion of competency versus the desirability of expertise: Seeking a common standard for support professions in sport. Sports Medicine, 45, 1-7. doi:10.1007/s40279-014-0251-1 
Collins, D. J., Collins, L., \& Willmott, T. (2016). Over egging the pudding? Comments on Ojala and Thorpe. International Sport Coaching Journal, 3, 90-93. doi:10.1123/iscj.2015-0068

Collins, L., Carson, H. J., \& Collins, D. (2016). Metacognition and professional judgment and decision making in coaching: Importance, application and evaluation. International Sport Coaching Journal, Manuscript submitted for review.

Collins, L., \& Collins, D. (2015). Integration of professional judgement and decision-making in high-level adventure sports coaching practice. Journal of Sports Sciences, 33, 622633. doi:10.1080/02640414.2014.953980

Collins, L., \& Collins, D. (2016a). Professional judgement and decision-making in adventure sports coaching: The role of interaction. Journal of Sports Sciences, 34, 1231-1239. doi:10.1080/02640414.2015.1105379

Collins, L., \& Collins, D. (2016b). Professional judgement and decision making in the planning process of high level adventure sports coaching practice. Journal of Adventure Education and Outdoor Learning, Advane online publication. doi:10.1080/14729679.2016.1162182

Corrie, S., \& Callahan, M. M. (2000). A review of the scientist-practitioner model: Reflections on its potential contribution to counselling psychology within the context of current health care trends. British Journal of Medical Psychology, 73, 413-427. doi:10.1348/000711200160507

Culver, D. M., \& Trudel, P. (2006). Cultivating coaches' communities of practice: Developing the potential for learning through interactions. In R. L. Jones (Ed.), Sports (pp. 97-112). Abingdon: Routledge.

Davids, K., Button, C., \& Bennett, S. (2008). Dynamics of skill acquisition: A constraints-led approach. Champaign, IL: Human Kinetics.

Demers, G., Woodburn, A. J., \& Savard, C. (2006). The development of an undergraduate competency-based coach education program. The Sport Psychologist, 20, 162-173 
Giannini, J. M., Krane, V., \& Hodge, K. (1990). Educational needs of elite U.S. national team, pan American, and Olympic coaches. Journal of Teaching in Physical Education, 9, 332-344.

Gibbons, M., Limoges, C., Nowotny, H., Schwartzman, S., Scott, P., \& Trow, M. (1994). The new production of knowledge: The dynamics of science and research in contemporary societies. London: Sage.

Gray, D. E. (2014). Doing research in the real world (3rd ed.). London: Sage.

Hambrick, D. C. (1994). Academy of Management Review, 19, 11-16.

Huxley, A. (1933). Texts and pretexts: An anthology with commentaries. London: Harper \& Brothers Publishers.

Illeris, K. (2004). A model for learning in working life. Journal of Workplace Learning, 16, 431-441. doi:10.1108/13665620410566405

Jones, R. L. (Ed.) (2006). The sports coach as educator: Re-conceptualising sports coaching. London: Routledge.

Jones, R. L., \& Turner, P. (2006). Teaching coaches to coach holistically: Can Problem-Based Learning (PBL) help? Physical Education and Sport Pedagogy, 11, 181-202. doi:10.1080/17408980600708429

Kelchtermans, G. (2005). Teachers' emotions in educational reforms: Self-understanding, vulnerable commitment and micropolitical literacy. Teaching and Teacher Education, 21,995-1006. doi:10.1016/j.tate.2005.06.009

Kelchtermans, G. (2009). Who I am in how I teach is the message: Self- understanding, vulnerability and reflection. Teachers and Teaching, 15, 257-272. doi:10.1080/13540600902875332

Kennedy, P., \& Llewelyn, S. (2001). Does the future belong to the scientist practitioner? The Psychologist, 14, 74-78.

Kruger, J., \& Dunning, D. (1999). Unskilled and unaware of it: How difficulties recognising one's own incompetence lead to inflated self assessments. Journal of Personality and Social Psychology, 77, 1121-1134. 
Lane, D. A., \& Corrie, S. (2006). The modern scientist-practitioner: A guide to practice in psychology. Hove: Routledge.

Lueger, R. J. (2002). Practice-informed research and research-informed psychotherapy. Journal of Clinical Psychology, 58, 1265-1276. doi:10.1002/jclp.10110

MacLean, D., MacIntosh, R., \& Grant, S. (2002). Mode 2 management research. British Journal of Management, 13, 189-207. doi:10.1111/1467-8551.00237

MacNamara, Á., \& Collins, D. (2015). Twitterati and Paperati: Evidence versus popular opinion in science communication. British Journal of Sports Medicine, Advanced online publication. doi:10.1136/bjsports-2015-094884

McCullick, B. A., Belcher, D., \& Schempp, P. G. (2005). What works in coaching and sport instructor certification programs? The participants' view. Physical Education \& Sport Pedagogy, 10, 121-137. doi:10.1080/17408980500105015

McDonald, M. P., \& Mooney, C. Z. (2011). "Pracademics": Mixing an academic career with practical politics. PS: Political Science \& Politics, 44, 251-253. doi:10.1017/S1049096511000035

McNiff, J., \& Whitehead, J. (2009, September). Explicating a new epistemology for educational knowledge with educational responsibility. Paper presented at the symposium of the British Educational Research Association, University of Manchester.

Nelson, L., Cushion, C., \& Potrac, P. (2013). Enhancing the provision of coach education: The recommendations of UK coaching practitioners. Physical Education and Sport Pedagogy, 18, 204-218. doi:10.1080/17408989.2011.649725

Nelson, L., Groom , R., \& Potrac, P. (2016). Learning in sports coaching: Theory and application. Abingdon: Routledge.

Ojala, A.-L., \& Thorpe, H. (2015). The role of the coach in action sports: Using a problembased learning approach. International Sport Coaching Journal, 2, 64-71. doi:10.1123/iscj.2014-0096 
Peters, S. (2012). The chimp paradox: The mind management programme to help you achieve success, confidence and happiness. London: Vermillion.

Piggott, D. (2012). Coaches' experiences of formal coach education: A critical sociological investigation. Sport, Education and Society, 17, 535-554. doi:10.1080/13573322.2011.608949

Piggott, D. (2015). The Open Society and coach education: A philosophical agenda for policy reform and future sociological research. Physical Education and Sport Pedagogy, 20, 283-298. doi:10.1080/17408989.2013.837435

Plas y Brenin. (2018). Adventure Spoprts Coachning Conference, Janurary, 11-12 2018

Posner, P. L. (2009). The pracademic: An agenda for re-engaging practitioners and academics. Public Budgeting \& Finance, 29, 12-26. doi:10.1111/j.15405850.2009.00921.x

Price, W. T. (2001). A pracademic research agenda for public infrastructure: Models/results public works practitioners need to know. Public Works Management \& Policy, 5, 287-296. doi:10.1177/1087724x0154004

Raelin, J. A. (2008). Work-based learning: Bridging knowledge and action in the workplace. San Francisco, CA: Jossey-Bass.

Robson, C. (2011). Real world research (3rd ed.). West Sussex: John Wiley \& Sons.

Rushall. B. S (2003). Coaching Development and the Second Law of Thermodynamics (or Belief-Based Versus Evidence-Based Coaching Development [Online] San Diego University

Sackett 1996. Evidence based medicine: what it is and what it isn't https://www.cebma.org/wp-content/uploads/Sackett-Evidence-Based-Medicine.pdf

Saury, J., \& Durand, M. (1998). Practical knowledge in expert coaches: On-site study of coaching in sailing. Research Quarterly for Exercise and Sport, 69, 254-266. doi:10.1080/02701367.1998.10607692 
Schempp, P. (1998). The dynamics of human diversity in sport pedagogy scholarship.

Sociology of Sport on line, 1. Retrieved from

http://pyysed.otago.ac.nz/sosol/vlil/vlila8.htm

Schommer, M. A. (1994). Synthesising epistemological belief of research: Tentative understandings and provocative confusions. Educational Psychology Review, 6, 293319. doi:10.1007/BF02213418

Schön, D. (1983). The reflective practitioner: How professionals think in action. Aldershot, UK: Ashgate.

Schwartz, B. (2011). Practical wisdom and organizations. Research in Organizational Behavior, 31, 3-23. doi:10.1016/j.riob.2011.09.001

Shapiro, D. (2002). Renewing the scientist-practitioner model. The Psychologist, 15, 232234.

Syed, M. (2010). Bounce: The myth of talent and the power of practice. London: Fourth Estate.

Taylor, W. G., \& Collins, L. (2016). Jack Mezirow: Transformative learning in coaching. In L. Nelson, R. Groom , \& P. Potrac (Eds.), Learning in sports coaching: Theory and application (pp. 150-160). Abingdon: Routledge.

Tranfield, D., \& Starkey, K. (1998). The nature, social organization and promotion of management research: Towards policy. British Journal of Management, 9, 341-353. doi:10.1111/1467-8551.00103

Trudel, P., Culver, D., \& Werthner, P. (2013). Looking at coach development from the coachlearner's perspective: Considerations for coach development administrators. In P. Potrac, W. Gilbert, \& J. Denison (Eds.), Routledge Handbook of Sports Coaching (pp. 375-387). Abingdon: Routledge.

Trudel, P., \& Gilbert, W. D. (2006). Coaching and coach education. In D. Kirk, M. O’Sullivan, \& D. McDonald (Eds.), Handbook of Physical Education (pp. 516-539). London: Sage. 
Tunison, S. (2016). Cultivating knowledge: Promoting research to enrich everyday practice. Boston: Sense Publishers.

Volpe, M. R., \& Chandler, D. (2001). Resolving and managing conflicts in academic communities: The emerging role of the "pracademic". Negotiation Journal, 17, 245255. doi:10.1111/j.1571-9979.2001.tb00239.x

Werthner, P., Culver, D., \& Trudel, P. (2012). An examination of a large-scale coach education program from a constructivist perspective. In R. Schinke (Ed.), Sport psychology insights. New York: Nova Science Publishers.

Werthner, P., \& Trudel, P. (2006). A new theoretical perspective for understanding how coaches learn to coach. The Sport Psychologist, 20, 198-212

Wheatley, M. J. (1999). Leadership and the new science: Discovering order in a chaotic world. San Francisco, CA: Berrett-Koehler Publishers.

Winter, S., \& Collins, D. (2015). Where is the evidence in our sport psychology practice? A UK perspective on the underpinnings of action. Professional Psychology: Research and Practice, 46, 175-182. doi:10.1037/pro0000014 